\title{
A Simulation study of video conferencing system over IEEE 802.11n wireless LAN
}

\author{
Omar M. Ali, Yazen S. Sheet, Firas S. Alsharbaty
}

Department of Electrical Engineering, Mosul University, Iraq

\begin{tabular}{l}
\hline \hline Article Info \\
\hline Article history: \\
Received Apr 26, 2019 \\
Revised Dec 13, 2019 \\
Accepted Jan 7, 2020 \\
\hline
\end{tabular}

Keywords:

Channel bandwidth

IEEE 802.11n

Video conferencing

\begin{abstract}
Wireless local area network (WLAN) is the core of the classic wireless communications systems and owns the infrastructure which wide spreads in many regions in the world. IEEE $802.11 \mathrm{n}$ is an attractive standard of WLAN and offers a data capacity of the cell. This paper estimates the maximum limits of the IEEE 802.11n standard cell as a term of number of users which are successfully served by the cell in case of video conference application. The results shown that, the cell of $802.11 \mathrm{n}$ could serve about 9 users under the service of video conference in case of $20 \mathrm{MHz}$ channel bandwidth before congestion occurs while the $40 \mathrm{MHz}$ channel could support 18 users.
\end{abstract}

Copyright @ 2020 Institute of Advanced Engineering and Science. All rights reserved.

\section{Corresponding Author:}

Omar M. Ali,

Department of Electrical Engineering,

Mosul University,

Ninava, Iraq.

Email: omarddr83@gmail.com

\section{INTRODUCTION}

In recent years, development of mobile devices, such as laptops and smartphones has increased their popularity and thus the wireless network has become the preferred network of users, because it allows them to connect to the Web and ambulate within a specific geographical area $[1,2]$. On the other hand, the applications used in these devices have become sophisticated and this has resulted in an increase in the amount of data to be transferred over the wireless network [3-5]. The wireless network receives the attention of researchers to improve the quality of the communication or to study the possibility of running some applications within the wireless network.

The IEEE 802.11 standard contains a series of versions, each one has a technological development over many years. In the 1990s, the first wireless LAN standard emerged which supports a data rate up to $2 \mathrm{Mbps}$. However, the $802.11 \mathrm{~b}$ wireless standard was created, supporting data rate up to $11 \mathrm{Mbps}$ using DSSS and FHSS technologies. It operates within the $2.4 \mathrm{GHz}$ band. The $802.11 \mathrm{a}$ wireless standard has a data rate of up to $54 \mathrm{Mbps}$ using the OFDM technology. It created in 1999 and deals with the $5 \mathrm{GHz}$ band. Networks, which used $802.11 \mathrm{~g}$ operate at $2.4 \mathrm{GHz}$ band, the same band as $802.11 \mathrm{~b}$, but the $802.11 \mathrm{~g}$ uses OFDM technology that allows data rate speed to reach 54 Mbps [6-8].

The IEEE 802.11n standard was introduced in 2009. It is based on many accelerator technologies such as the Multiple Input Multiple Output (MIMO) technology, the frame aggregation, channel bonding, and the block acknowledgment mechanism to support high data rate [6]. IEEE802.11n operates on either the $2.4 \mathrm{GHz}$ or the $5 \mathrm{GHz}$ band, it supports two channel bandwidth $20 \mathrm{MHz}$ and $40 \mathrm{MHz}[6,7]$. The IEEE $802.11 \mathrm{n}$ could support the data rate of $6.5 \mathrm{Mbps}$ in the case of the following conditions $(20 \mathrm{MHz}$ channel, 800ns guard interval GI mode, and 1x1 MIMO technology) while the high level of $802.11 \mathrm{n}(600 \mathrm{Mbps})$ is achieved under the following conditions $(40 \mathrm{MHz}$ channel, $400 \mathrm{~ns}$ guard interval GI mode, and $4 \mathrm{x} 4 \mathrm{MIMO}$ 
technology) [9-12, 8]. A video conferencing is one of the most important applications currently used as an easy way to make a communication between peoples [13]. It is used to hold meetings between managers and employees, to conduct distance learning sessions, and etc [14]. Video conferencing requires a relatively high data rate because it sends video signal data. This is an application that drains network resources, whether wired or wireless[15]. Research has been carried out to calculate the upper limits of the total delay time for video conferencing and the time lag. The acceptable delay in conference application to work well is less than $150 \mathrm{msec}$ and the delay variance is not more than $30 \mathrm{msec}[14,16]$.

If the video is transferred without any compression process, it will consume a lot data rate [17] that the wired network may not be able to carry it, and therefore wireless network will not work. Accordingly video compression is made on the video at real time before being sent over the network [18, 19]. As the video conference began, several versions of real time video compressors have been created like (H.261, H263, H.264, and H.265) to minimize the amount data rate of the transmitted video [10-22].

\section{LITERATURE REVIEW}

The 802.11n wireless network standard received the attention of researchers, and several studies have been conducted to test the performance of this wireless standard. In [23], the researchers conducted a study to estimate the capacity of a multimedia applications such as the IPTV and VoIP over wireless LAN that operates according to the $802.11 \mathrm{n}$ wireless standard. Their results showed a $25 \%$ improvement in IPTV application capacity when the TFRC protocol was adopted within the transport layer with the TCP protocol.

S. Dhar and S. Chatterjee in [24] conducted a study to assess the performance of different types of sound compression techniques used in the application of VOIP when it working over the wireless LAN standard IEEE802.11n. The results of the study showed that the use of the sound compressor type G.711 gives satisfactory results in terms of the quality of the audio in addition to the value of the delay. Evizal A. Kadir and et al in [25], tested the effect of some parameters in the application of distance learning over the wireless network standard of IEEE802.11n. Their test results showed that the WLAN can propping up 100 users dealing with the distance learning application at the same time. In [26], the researchers tested the 802.11n wireless LAN QoS provided by their proposed technology to support real-time applications. Their results showed that their proposed method improved the quality of service for real-time applications. Bera Bulut and et al in [11], investigated the advantages of using AL-FEC to transmit high-quality video using Multicast over the 802.11n wireless LAN with the use of MIMO technology, The study concluded that AL-FEC can be used to improve both reliability and transport efficiency, if MIMO channels has low spatial correlations

\section{PROBLEM STATEMENT}

Wireless LAN is limited in bandwidth and influenced by external factors such as noise and interference. Using WLAN in transfer data of real-time applications such as video conferencing poses many challenges. On the other hand, most of the previous relevant research calculates the variables of the wireless network based on a limited number of users, while it is necessary to calculate the largest number of users in the service that the wireless network can afford for real time applications before the collapse of the wireless network. After knowing the break point, service providers will have a prior knowledge of their wireless network capabilities.

\section{RESEARCH METHOD}

This paper builds a model in order to simulate a wireless local area network (WLAN) based on the standard of $802.11 \mathrm{n}$ in case of video conference application. There are two main scenarios for the model dealing with the video conference application, the first one offers the basic concept of this standard where the conditions of the basic level of the standard and bandwidth equal to $20 \mathrm{MHz}$. This scenario aims to measure the basic capacity of the IEEE802.11n cell without any enhancement equipments. The second scenario estimates the capacity of IEEE802.11n cell in case of upgrade the bandwidth to $40 \mathrm{MHz}$. The model of this research is built using Reverbid software and offers many performance metrics with the increment of users number. The basic components of the models are a server connected to wireless router supports the standard of 802.11n with wireless users, as shown in Figure 1. The complete assumptions of the model are listed in Table 1. 


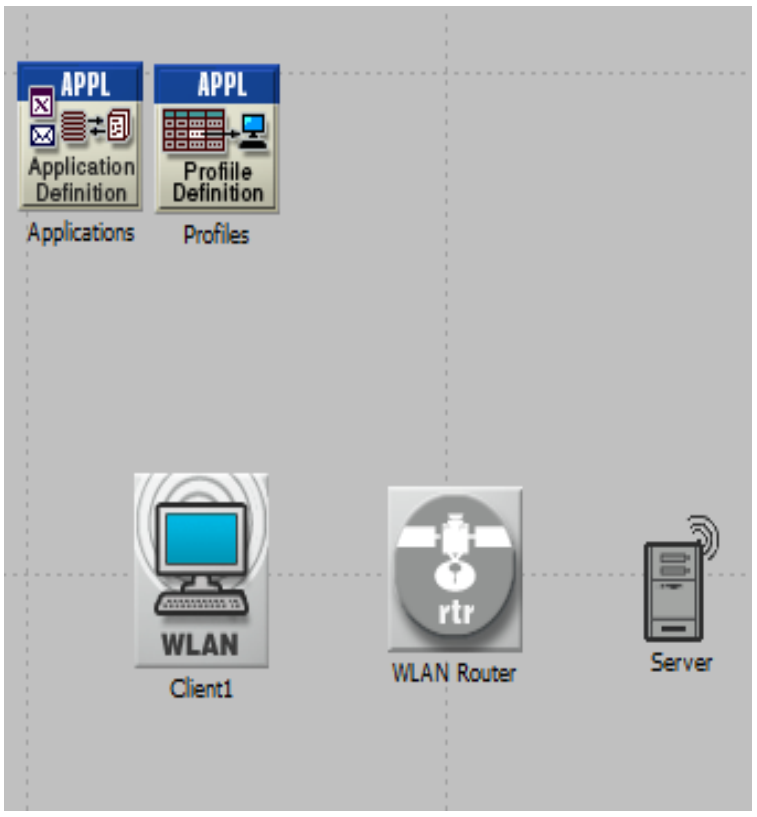

(a)

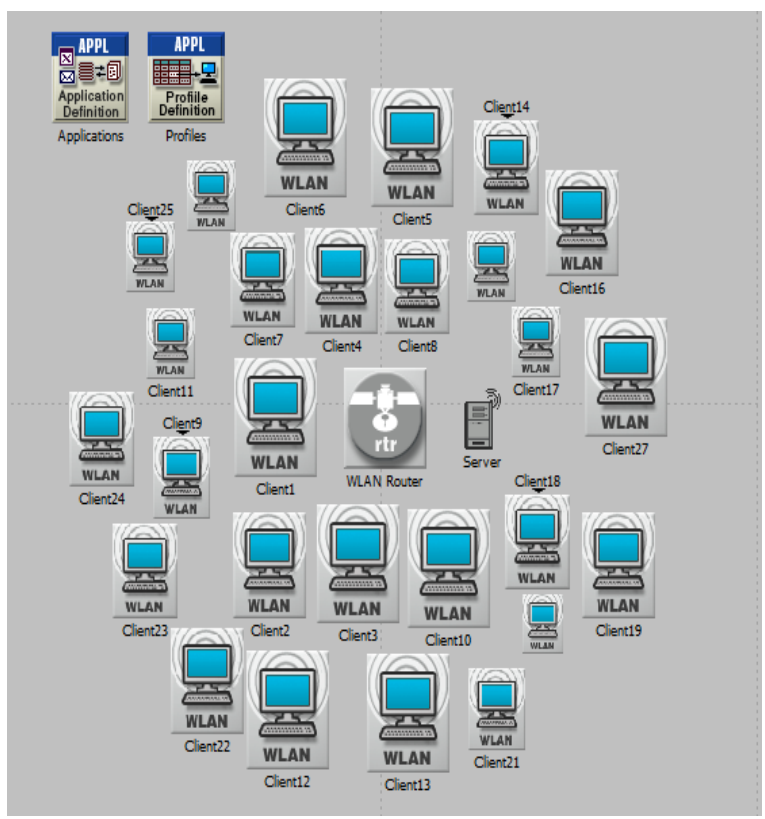

(b)

Figure 1. The Wireless network models: (A) Basic model, (B) Complate model

Table 1. Assumptions were adopted in the wireless model

\begin{tabular}{ll}
\hline \multicolumn{1}{c}{ Parameter } & \multicolumn{1}{c}{ Value } \\
\hline Simulation Area & Office network (100x100) meter \\
Network architecture & Client-Server \\
WLAN standard & IEEE 802.11n \\
WLAN band & $2.4 \mathrm{GHz}$ \\
No. of spatial streams & 1 \\
Guard Interval (GI) & $400 \mathrm{~ns}$ \\
Channel bandwidth & $20 \mathrm{MHz} / 40 \mathrm{MHz}$ \\
Data Rate & $65 \mathrm{Mbps}$ (Base) \\
Buffer size & $2 \mathrm{MB}$ \\
Network Application & Video Conference \\
Video conference data rate & $1024 \mathrm{Kbps}$ \\
Transmission protocol & UDP \\
Simulation time & 300 seconds \\
\hline
\end{tabular}

The method of this research depends on three main aspects:

a) End to End delay $\leq 150 \mathrm{msec}$.

b) Max. Jitter $\leq 30 \mathrm{msec}$.

c) The ratio of traffic $\geq 99 \%$.

\section{RESULTS AND DISCUSSIONS}

After building an IEEE802.11n wireless LAN model in the Riverbed Software Modeler and configuring the Riverbed with the required settings, the simulation was performed and the following results were obtained.

\subsection{Video conference MAX. packet delay variation}

Table 2 shows the MAX. Packet Delay Variation of video conferencing application for both IEEE802.11n channel bandwidths. We can see that the delay variance starts to appear significantly if the number of connected nodes reaches 15 for a $20 \mathrm{MHz}$ channel bandwidth. On the other hand, the increase in delay variation is noticeable when the number of connected nodes becomes equal to 24 for the $40 \mathrm{MHz}$ channel. 


\begin{tabular}{|c|c|c|}
\hline \multirow{2}{*}{ No. of users } & \multicolumn{2}{|c|}{ MAX. Packet Delay Variation $(\leq)$} \\
\hline & $20 \mathrm{MHz}$ & $40 \mathrm{MHz}$ \\
\hline 1 & $1.80 \mathrm{E}-7$ & $9.57 \mathrm{E}-8$ \\
\hline 3 & $1.32 \mathrm{E}-6$ & $2.97 \mathrm{E}-7$ \\
\hline 6 & $4.96 \mathrm{E}-6$ & $2.30 \mathrm{E}-6$ \\
\hline 9 & $8.43 \mathrm{E}-6$ & $3.03 \mathrm{E}-6$ \\
\hline 12 & $6.67 \mathrm{E}-4$ & $6.28 \mathrm{E}-6$ \\
\hline 15 & $2.29 \mathrm{E}-2$ & $8.59 \mathrm{E}-6$ \\
\hline 18 & $3.79 \mathrm{E}-2$ & $3.35 \mathrm{E}-4$ \\
\hline 21 & & $1.09 \mathrm{E}-3$ \\
\hline 24 & & $2.98 \mathrm{E}-3$ \\
\hline 27 & & $1.17 \mathrm{E}-2$ \\
\hline
\end{tabular}

\subsection{Video conference packet end-to-end delay (Sec.)}

Figure 2 shows the relationship between video conferencing packet E2E delay and the increase of users number for both IEEE802.11n channel bandwidths. It should be noted that the increase in the end-to-end delay value is directly proportional to the increasing number of users in each channel bandwidth. At $20 \mathrm{MHz}$ channel bandwidth, the E2E delay exceeds the video conferencing failure threshold delay within 15 users while 24 users encroach the failure threshold delay at $40 \mathrm{MHz}$ channel bandwidth.

\subsection{Percentage of video conference traffic received/traffic sent}

Figure 3 Shows the percentage traffic received / traffic sent of the video conferencing application for each IEEE 802.11n channel bandwidths. It is noted that the video conference is working correctly until the received video became less than the video being sent because the $802.11 \mathrm{n}$ reach the throttle stage. At $20 \mathrm{MHz}$ channel bandwidth the video conference work properly with 9 users, but $40 \mathrm{MHz}$ channel bandwidth served properly 18 users.

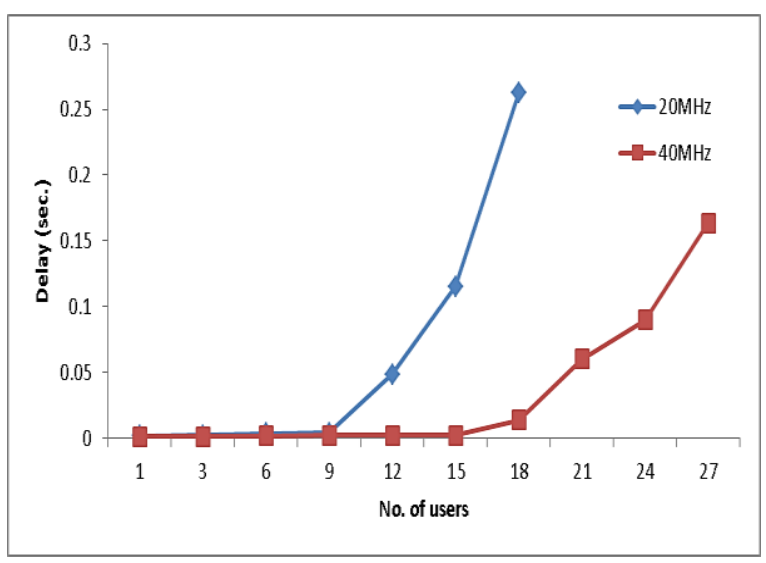

Figure 2. Video conference packet end-to-end delay

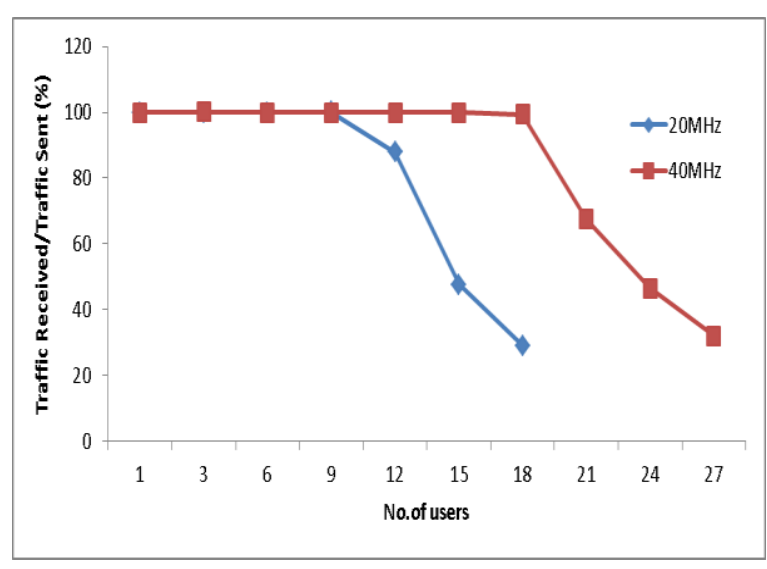

Figure 3. Percentage of video conference TR/TS

\subsection{WLAN data dropped}

Figure 4 Shows that data drop (Buffer Overflow) will appear when the number of users exceed 9 users at $20 \mathrm{MHz}$ channel bandwidth while data drop will appear when the number of users exceed 18 users for $40 \mathrm{MHz}$ channel bandwidth. This happened because the number of users increased to the point where $802.11 \mathrm{n}$ could not transfer more data for each bandwidths.

\subsection{Wireless LAN delay (Sec)}

Figure 5 Shows that the delay of the wireless network is increased as the amount of transmitted video data increased and becomes higher when the network reaches the bottleneck limit. The delay of the wireless network starts at a high rate when the number of users becomes greater than 9 in the case of a $20 \mathrm{MHz}$ channel bandwidth, while the delay increase when the number of users exceeds 15 at $40 \mathrm{MHz}$ channel bandwidth. 


\subsection{Wireless LAN throughput (bits/Sec)}

Figure 6 shows that the throughput of the wireless network is increased as the amount of transmitted video data increased until the wireless network reaches the bottleneck limit. At this point the throughput begins to decrease due to the lack of network capacity for such data.

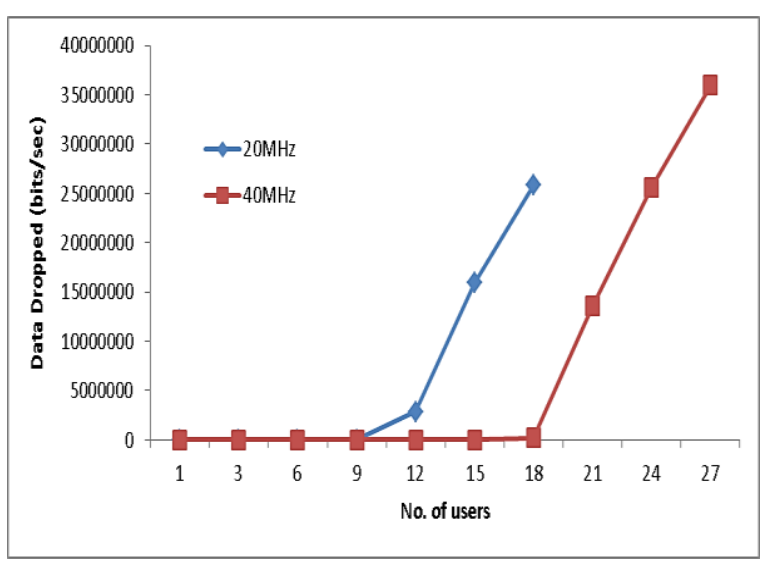

Figure 4. Data dropped in WLAN due to buffer overflow

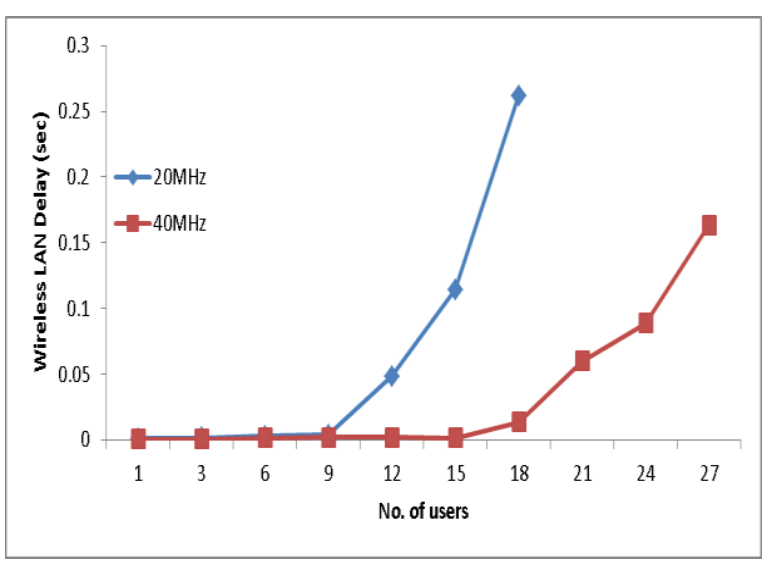

Figure 5. Wireless LAN delay

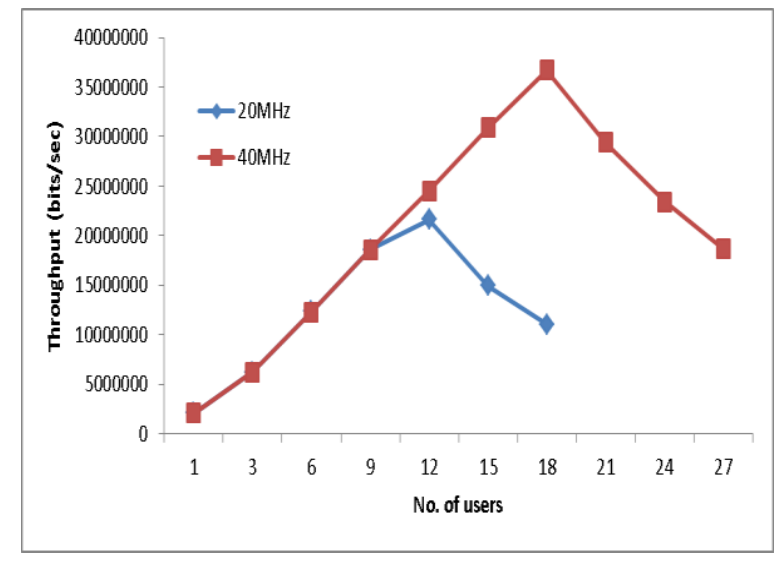

Figure 6. Wireless LAN throughput

\section{CONCLUSION}

As mentioned before, this research studied the capacity of $802.11 \mathrm{n}$ wireless local area network (WLAN) cell as a term of users number in case of video conference application. The results of simulation shown that the cell of 802.11n standard could support 9 users successfully (without data lost from received traffic point of view) in case of the bandwidth equal to $20 \mathrm{MHz}$. Whilst the number of users which are successfully supported by the cell of $802.11 \mathrm{n}$ standard is increased to 18 users in case of $40 \mathrm{MHz}$ channel bandwidth for the same application.

\section{ACKNOWLEDGEMENTS}

This work was supported by Electrical Department, Engineering College, Mosul University.

\section{REFERENCES}

[1] C. Li, C. Peng, S. Lu, X. Wang and R. Chandra, "Latency-aware rate adaptation in 802.11n home networks," 2015 IEEE Conference on Computer Communications (INFOCOM), Kowloon, pp. 1293-1301, 2015.

[2] L. Yu, H. Li and W. Li, "Wireless Cooperative Video Coding Using a Hybrid Digital-Analog Scheme," in IEEE Transactions on Circuits and Systems for Video Technology, vol. 25, no. 3, pp. 436-450, Mar. 2015. 
[3] T. Kaewkiriya, "Performance comparison of Wi-Fi IEEE 802.11ac and Wi-Fi IEEE 802.11n," 2017 2nd International Conference on Communication Systems, Computing and IT Applications (CSCITA), Mumbai, pp. 235-240, 2017.

[4] J. Pokhrel et al, "Performance Evaluation of Video transmission over 802.11n wireless network: A MAC layer perspective," 2014 International Conference on Smart Communications in Network Technologies (SaCoNeT), IEEE, 2014.

[5] Q. Chen and D. Wu, "Delay-Rate-Distortion Model for Real-Time Video Communication," in IEEE Transactions on Circuits and Systems for Video Technology, vol. 25, no. 8, pp. 1376-1394, Aug. 2015.

[6] O. O. Olusegun and C. E. Tan, "TCP throughput efficiency enhancement in IEEE 802.11n network," 2013 8th International Conference on Information Technology in Asia (CITA), Kota Samarahan, pp. 1-5, 2013.

[7] W. Osterhage, "Wireless Network Security," Published by CRC Press Taylor \& Francis Group, pp. 20-27, 2018.

[8] D. Maraj and A. Maraj, "Performance analysis of WLAN 802.11g/n standards using OPNET (Riverbed) application," 2015 57th International Symposium ELMAR (ELMAR), Zadar, pp. 129-132, 2015.

[9] S. K. Debnath et al, "A Throughput Estimation Model for IEEE 802.11n MIMO Link in Wireless LocalArea Networks," 3rd International Conference on Computer and Communication Systems (I2S), IEEE, 2018.

[10] A. Srivastava et al, "Coverage Improvement of IEEE 802.11n Based Campus Wide Wireless LANs," International Conference on Advances in Communication and Computing Technology (ICACCT), IEEE, 2018.

[11] B. Bulut et al, "Cross-Layer Design of Raptor Codes for Video Multicast over 802.1ln MIMO Channels," 26th International Symposium on Personal, Indoor and Mobile Radio Communications - (PIMRC): Mobile and Wireless Networks, IEEE, 2015.

[12] R. Karmakar, S. Chattopadhyay and S. Chakraborty, "Impact of IEEE 802.11n/ac PHY/MAC High Throughput Enhancements on Transport and Application Protocols-A Survey," in IEEE Communications Surveys \& Tutorials, vol. 19, no. 4, pp. 2050-2091, Fourthquarter 2017.

[13] A. Bahnasse et al, "Dynamic Multipoint Virtual Private Network influence on Video Conferencing Quality of Service," 2019 2nd International Conference on Computer Applications \& Information Security (ICCAIS), 2019.

[14] F. S. Alsharbaty et al, "Performance Evaluation of Adaptive Real Time Application in the Cell of IEEE 802.16e Standard," Journal of Adv Research in Dynamical \& Control Systems, vol. 10, 09-Special Issue, 2018.

[15] P. Laddha and S.Ramalingam, "Bitrate and Complexity Optimizations for Video Conferencing Systems," 2016 IEEE International Conference on Consumer Electronics (ICCE), IEEE, 2016.

[16] A. Tesfamicael et al, "Modeling for a QoS-Efficient Real-Time Video Conferencing System in the Cloud," 2018 26th International Conference on Software, Telecommunications and Computer Networks (SoftCOM), IEEE, 2018.

[17] Q. Shi and H Sun, "Image and video compression for multimedia engineering: Fundamentals, algorithms, and standards," CRC press, pp. 3-4, 2008.

[18] A. Liu, W. Lin, M. Paul, F. Zhang and C. Deng, "Optimal Compression Plane for Efficient Video Coding," in IEEE Transactions on Image Processing, vol. 20, no. 10, pp. 2788-2799, Oct. 2011

[19] E. Richardson, "The H.264 Advanced Video Compression Standard," John Wiley \& Sons Ltd., 2010.

[20] I. U. Khan et al, "Performance Analysis of H.264 Video Decoder: Algorithm and Applications," International Conference on Energy Economics and Environment (ICEEE), IEEE, 2015.

[21] N. Minallah et al, "Performance Analysis of H.265/HEVC (HighEfficiency Video Coding) with reference to Other Codecs," 13th International Conference on Frontiers of Information Technology, IEEE, 2015.

[22] Y. Yoon, M. Kim, S. Lee, B. Lee, S. J. Hyun and K. Lee, "Performance analysis of H.264/AVC, H.264/SVC, and VP8 over IEEE 802.11 wireless networks," 2012 IEEE Symposium on Computers and Communications (ISCC), Cappadocia, pp. 000151-000156, 2012.

[23] S. Saleh and et al, "Capacity Analysis of Combined IPTV and VoIP over IEEE 802.11n," 38th Annual IEEE Conference on Local Computer Networks, IEEE, 2013.

[24] S. Dhar and S Chatterjee, "A Study of Voip Codecs Performance Over Ieee 802.11n," 2017 Devices for Integrated Circuit (DevIC), IEEE, 2017.

[25] E. A. Kadir et al, "Performance Analysis of Wireless LAN 802.11n Standard for e-Learning," Fourth International Conference on Information and Communication Technologies (ICoICT), IEEE, 2016.

[26] E. Charfi et al, "QoS Support of Voice/video Services under IEEE 802.11n WLANs," 9th International Symposium on Communication Systems, Networks \& Digital Sign (CSNDSP), IEEE, 2014.

\section{BIOGRAPHIES OF AUTHORS}

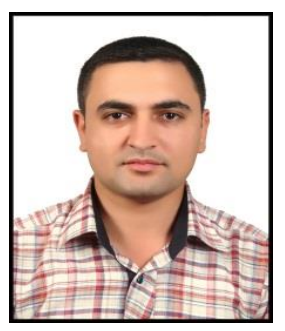

Omar M. Ali completed the B.S. in electrical engineering/electronic and communication from University of Mosul, Iraq, in 2006 and received the M.Sc degree in computer networks in 2012 from Mosul University. He interested in the field of computer networks and communication and he had publication papers in WLAN (802.11a, 802.11g, and 802.11n). He has been working as a communications lecturer and computer networks lecturer at University of Mosul since 2012. $\mathrm{He}$ is a memeber of computer networks lab in Electrical Dept/Engineering College. 


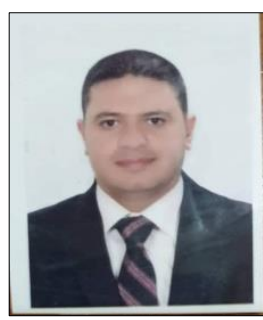

Yazen S. Sheet completed the B.S. in electrical engineering/electronic and communication from University of Mosul, Iraq, in 2005 and received the M.Sc degree in computer networks in 2011 from Mosul University. He interested in the field of computer networks and communication and he had publication papers in 802.16e. He has been working as a communications lecturer and computer networks lecturer at University of Mosul since 2012. He is a memeber of computer networks lab in Electrical Dept/Engineering College.

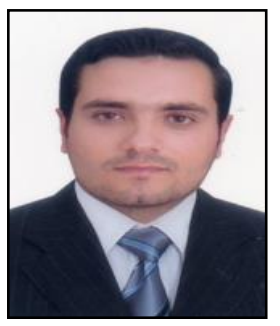

Firas S. Alsharbaty completed the B.S. in electrical engineering/electronic and communication from University of Mosul, Iraq, in 2007 and received the M.Sc degree in computer networks and communication in 2010 from Mosul University. He interested in the field of computer networks and communication and he had publication papers in WiMAX (802.16d, 802.16e), Mesh, LTE and zigbee. He has been working as a communications lecturer and computer networks lecturer at University of Mosul since 2011. He is a memeber of computer networks lab in Electrical Dept/Engineering College. 